\section{Remoción del barro dentinario y erosión sobre el sustrato al utilizar diferentes soluciones ácidas}

\section{Smear layer removal and erosion on the substrate using different acid solutions}

\section{Resumen}

Objetivo: Evaluar con microscopía electrónica de barrido (MEB) la remoción de barro y erosión al irrigar los canales radiculares con cuatro soluciones ácidas. Métodos: Se utilizaron 30 premolares inferiores uniradiculares divididos en cinco grupos según tipo de irrigación: Grupo 1 Control: $\mathrm{NaOCl}$ 5,25\%. Grupo 2: $\mathrm{NaOCl} 5,25 \%$ + ácido etilendiaminotetraacético (EDTA) 17\%. Grupo 3: $\mathrm{NaOCl} 5,25 \%$ + ácido maleico 5\%. Grupo 4: $\mathrm{NaOCl} 5,25 \%$ + ácido cítrico 10\%. Grupo 5: $\mathrm{NaOCl} 5,25 \%$ + ácido fosfórico 37\%. Se realizaron 90 microfotografías con MEB a 5000x a 2, 6 y $10 \mathrm{~mm}$ de la longitud de trabajo. Resultados: Se encontró diferencia significativa de la remoción del barro dentinario entre el grupo control y los demás grupos $(p<0,05)$. Hubo diferencia significativa entre el grupo 4 y grupos 2 y 5 . No hubo diferencia significativa entre los grupos 3 y 4 , ni entre los grupos 2,3 y 5 . No hubo diferencia significativa de remoción entre tercios del conducto radicular $(p=0,07)$. Respecto a la erosión no se encontró diferencia significativa entre irrigantes $(p<0,05)$. Tampoco se encontró diferencias a nivel de los tercios $(p=0,19)$. Conclusiones: $\mathrm{El} \mathrm{NaOCl} 5,25 \%$ + ácido maleico 5\% e $\mathrm{NaOCl} 5,25 \%$ + ácido cítrico $10 \%$ producen mayor remoción del barro dentinario. El $\mathrm{NaOCl} 5,25 \%$ + ácido fosfórico $37 \%$ e $\mathrm{NaOCl} 5,25 \%$ + ácido cítrico $10 \%$ producen mayor erosión. No hubo diferencia de remoción ni de erosión entre los tercios del conducto. La combinación de $\mathrm{NaOCl} 5,25 \%$ + ácido maleico 5\% brindaría el mejor balance entre remoción y erosión.

Palabras clave: Ácido cítrico; Barro dentinario; EDTA; Erosión; Hipoclorito de sodio.
ISSN: 1560-9111

\section{Artículo Original}

Alicia Beatriz Labarta ${ }^{1, a}$, Liliana Gloria Sierra ${ }^{1, b}$

${ }^{1}$ Universidad de Buenos Aires. Facultad de

Odontología. Buenos Aires, Argentina.

a Especialista en Endodoncia. Máster en Educación Universitaria.

${ }^{\text {b }}$ Doctora en Odontología.

Correspondencia:

Alicia Beatriz Labarta.

Correo electrónico: doclabarta@hotmail.com Argerich $23961^{\circ} \mathrm{A}$. CP 1416. Buenos Aires. Argentina.

Coautora:

Liliana Gloria. Sierra

liglosierra@hotmail.com

Conflicto de intereses: Los autores declaran no tener conflictos de interés.

Fuente de financiamiento: No poseen

Fecha de recepción: 09/04/18

Fecha de aceptación: 08/05/18

( ) Los autores. Este artículo es publicado por la revista Odontología Sanmarquina de la Facultad de Odontología, Universidad Nacional Mayor de San Marcos. Este es un artículo de acceso abierto, distribuido bajo los términos de la licencia Creative Commons Atribucion - No Comercia_Compartir Igual 4.0 Internacional. (http://creativecommons.org/licenses/by-nc-sa/4.0/) que permite el uso no comercial, distribución y reproducción en cualquier medio, siempre que la obra original sea debidamente citada. 
between thirds of root canals ( $p=0.07$ ). About erosion, there was no significant difference between irrigants $(p<0.05)$. No significant differences were found between thirds of root canals $(p=0.19)$. Conclusions: $5.25 \% \mathrm{NaOCl}+5 \%$ maleic acid and $5.25 \% \mathrm{NaOCl}+$ $10 \%$ citric acid produce most smear layer removal. $5.25 \% \mathrm{NaOCl}+37 \%$ phosphoric acid and $5.25 \% \mathrm{NaOCl}+10 \%$ citric acid produce greater erosion. There was no difference of smear layer removal nor erosion between thirds of root canal. Combination of $5.25 \% \mathrm{NaOCl}+5 \%$ maleic acid would provide better balance between removal capacity and erosion degree.

Keywords: Citric acid; EDTA; Erosion; Smear layer; Sodium hypochlorite.

\section{Introducción}

La instrumentación manual o mecanizada producen una capa amorfa e irregular de barro dentinario. Esta capa contiene un componente orgánico y otro inorgánico; su grosor suele ser entre 1 a 5 micras variando según el tipo y filo del instrumento utilizado. Su profundidad de penetración en los túbulos dentinarios es de $40 \mu \mathrm{m}$ y se produce por una acción de capilaridad ${ }^{1}$.

El barro dentinario debe retirarse por completo de la superficie dentinaria porque puede albergar bacterias y ser una vía de reinfección. También porque limita la desinfección eficaz por falta de penetración del hipoclorito de sodio en los túbulos dentinarios e impide la penetración de la medicación intraconducto. Se ha observado que el barro dentinario actúa como una barrera entre el material de obturación y la pared dentinaria comprometiendo la adecuada obturación del conducto. Su presencia es sinónimo de conducto preparado y conformado ${ }^{2}$.

Durante años se ha tratado de buscar distintas sustancias para retirar el barro dentinario del conducto, sin embargo, no se ha encontrado la forma de eliminarlo completamente de los tres tercios del conducto. Dentro de estos se mencionan al hipoclorito de sodio, ácido etilendiaminotetraacético (EDTA), ácido maleico y ácido cítrico.

El hipoclorito de sodio es el irrigante más empleado en Endodoncia. Es un compuesto halogenado disolvente de restos pulpares y tiene muy buena acción bactericida, pero su capacidad para eliminar el barro dentinario es deficiente $^{3}$.

Se han utilizado diferentes soluciones ácidas para irrigar los conductos a lo largo del tiempo. El EDTA es el quelante universalmente utilizado; se recomienda un lavado con $5 \mathrm{ml}$ de EDTA $17 \%$ durante 1 minuto para una remoción eficiente puesto que en tiempos superiores erosiona la dentina peritubular ${ }^{4}$.

El ácido maleico es un ácido orgánico suave utilizado como acondicionador de dentina al realizar restauraciones adhesivas ${ }^{5}$. Hasta el momento existe poca evidencia científica relacionada con la evaluación de las diferentes concentraciones $(5 \%, 7 \%, 10 \%$ o $15 \%)$ de ácido maleico en la remoción del barro dentinario. Prabhu y cols. ${ }^{6}$ informaron que cuando se utiliza en una concentración superior al $7 \%$ causa daño a la dentina intertubular.
El ácido cítrico es un ácido orgánico que reacciona con los iones metálicos de la hidroxiapatita produciendo un quelato metálico. La dentina se reblandece cambiando su solubilidad y permeabilidad especialmente en la dentina peritubular rica en hidroxiapatita, incrementando el diámetro de los túbulos expuestos ${ }^{7}$.

Las soluciones quelantes actúan sobre la porción inorgánica y sobre las proteínas no colágenas (PNC) que componen la dentina. Así, las soluciones ácidas no sólo eliminan los iones de calcio de la dentina, sino también el calcio unido a las PNC. Debido a que el contenido de PNC disminuye en el tercio apical del conducto, el grado de descalcificación de las soluciones ácidas en esta porción del conducto es más bajo ${ }^{8}$. Las soluciones ácidas remueven la capa de barro dentinario, pero también erosionan la superficie dentinaria debido a una desmineralización y apertura tubular excesiva.

El objetivo de este trabajo fue evaluar in vitro con microscopía electrónica de barrido (MEB) el grado de remoción del barro dentinario y la erosión sobre el sustrato al irrigar con técnica pasiva y cuatro soluciones acidas (ácido maleico 5\%, ácido cítrico $10 \%$, ácido fosfórico $37 \%$ y ESTA 17\%), luego de instrumentar en forma rotatoria con Sistema Protaper Universal (Dentsply ๑, EE.UU).

\section{Métodos}

Se utilizaron 30 premolares inferiores, unirradiculares de humanos, obtenidos del banco de unidades dentarias. Se desconoció su identidad, pero cumplieron con las normas de bioseguridad establecidas por la American Dental Association (ADA) para su esterilización y conservación. Se incluyeron unidades dentarias con ápice cerrado, presencia de un sólo conducto (verificado radiográficamente) y curvaturas apicales menores a $30^{\circ}$ según la clasificación de Schneider ${ }^{1,9}$. Las unidades dentarias debían presentar longitud mayor a $18 \mathrm{~mm}$, ausencia de caries, fisuras y/o fracturas radiculares. Unidades dentarias con caries profundas, restauraciones, fracturas radiculares, ápices inmaduros o más de un conducto fueron descartadas.

Se estandarizó la longitud de las unidades dentarias en $18 \mathrm{~mm}$ con disco de carburo (Komet ${ }^{\oplus}$, Alemania). La muestra $(n=30)$ se dividió aleatoriamente en cinco grupos, de seis piezas cada uno $(\mathrm{n}=6)$, numerándose por grupo. Se usó piedra de diamante redonda 06 (Komet ${ }^{\circledR}$, Alemania), a alta velocidad y con refrigeración para rea- 
lizar la apertura cameral. Se rectificó con fresa Endo Z (Dentsply ${ }^{\oplus}$, EE.UU). Se estableció longitud de trabajo en $17 \mathrm{~mm}$ restándole un milímetro a la longitud en la que se estandarizó la muestra $(18 \mathrm{~mm})$.

En todos los grupos se realizó una preparación quirúrgica con sistema rotatorio Protaper Universal (Denstply $\oplus$, EE.UU.), instrumentando el tercio apical hasta una lima F3. Se accionaron los instrumentos de NITI a 350 rpm, montados en un motor reductor X Smart (Dentsply ${ }^{\oplus}$, EE.UU). Se descartó cada juego de instrumentos después del primer uso.

La conformación de los grupos fue realizada de la siguiente manera:

Grupo 1 Control: se irrigó con $5 \mathrm{ml}$ de $\mathrm{NaOCl}$ 5,25\% (Clorox ${ }^{\oplus}$, Argentina) entre cada instrumento durante un minuto. En este grupo no se usó solución ácida para la irrigación.

Grupo 2: se irrigó con $5 \mathrm{ml}$ de $\mathrm{NaOCl}$ 5,25\% (Clorox $๑$, Argentina) entre cada instrumento durante un minuto. Se usó como anteúltimo lavaje $5 \mathrm{ml}$ de solución de EDTA 17\% (Droguería Argentina ${ }^{\circledR}$, Argentina) durante un minuto.

Grupo 3: se irrigó con $5 \mathrm{ml}$ de $\mathrm{NaOCl}$ 5,25\% (Clorox $\oplus$, Argentina) entre cada instrumento durante un minuto. Se usó como anteúltimo lavaje $5 \mathrm{ml}$ de solución de ácido maleico 5\% (Droguería Argentina ${ }^{\oplus}$, Argentina) durante un minuto.

Grupo 4: se irrigó con $5 \mathrm{ml} \mathrm{de} \mathrm{NaOCl}$ 5,25\% (Clorox ${ }^{\circledR}$, Argentina) entre cada instrumento durante un minuto. Se usó como anteúltimo lavaje $5 \mathrm{ml}$ de solución de ácido cítrico 10\% (Droguería Argentina ${ }^{\circledR}$, Argentina) durante un minuto.

Grupo 5: se irrigó con $5 \mathrm{ml} \mathrm{de} \mathrm{NaOCl}$ 5,25\% (Clorox ${ }^{\circledR}$, Argentina) entre cada instrumento durante un minuto. Se usó como anteúltimo lavaje $5 \mathrm{ml}$ de ácido fosfórico 37\% (Droguería Argentina ${ }^{\oplus}$, Argentina) durante un minuto.

En todos los grupos se usaron dos jeringas plásticas de $5 \mathrm{ml}$ (Terumo ${ }^{\oplus}$, Argentina), una para cada irrigante y agujas descartables de 30 Gauges y $16 \mathrm{~mm}$, con salida lateral (Terumo ${ }^{\oplus}$, Argentina), las que penetraron en el conducto hasta $16 \mathrm{~mm}$ en todos los casos.

Como lavaje final se utilizaron $5 \mathrm{ml}$ de agua destilada estéril en todos los conductos (Laboratorio Klonal ๑, Argentina), para remover los precipitados formados durante la irrigación. Posteriormente los conductos se secaron con puntas de papel estériles calibre \# 30 (Dentsply ๑, EE.UU).

Hasta que se realizaron los cortes, las piezas se almacenaron en recipientes plásticos con tapa dentro de una estufa incubadora (Ingeniería Climax $₫$, Argentina), a $37^{\circ} \mathrm{C}$ y $100 \%$ de humedad.

Con un disco de carburo (Komet ${ }^{\circledR}$, Alemania), se marcó sobre las caras proximales de cada pieza, un surco profundo ${ }^{?}$.
El corte de las piezas en dos mitades se realizó con una prensa tipo $G$ adaptada para el caso a la cual se le colocaron dos hojas de bisturí de acero carbono $\mathrm{N}^{\circ} 20$ (Ribbel ${ }^{\oplus}$, India), en la parte inferior y superior, las cuales penetraron en las ranuras previamente realizadas, $\mathrm{y}$ al recibir la presión realizaron el corte. Cuando el conducto fue penetrado accidentalmente durante la preparación de las ranuras o se observó una superficie irregular luego de la separación, esas piezas fueron descartadas y reemplazadas por un nuevo espécimen ${ }^{9}$.

La mitad de cada diente, elegida al azar fue codificada y montada sobre bases de aluminio y se observaron en un microscopio electrónico de barrido ambiental (FEI, modelo QUANTA 250 FEG ๑, Japón), operado a 5 kV y $60 \mathrm{~Pa}$, a bajo vacío.

Se realizaron 90 microfotografías a una magnificación de 5000x, a 2, 6 y $10 \mathrm{~mm}$ de la longitud de trabajo.

Las imágenes fueron evaluadas por un sólo investigador que no conocía a qué grupos pertenecían las muestras pero que previamente fue sometido, para mejorar el nivel de concordancia al índice Kappa de Cohen.

Se utilizó la escala propuesta por Rome y cols. ${ }^{2}$ para analizar el grado de remoción:

$0=$ No barro dentinario (no hay barro dentinario sobre la superficie de la pared del conducto, todos los túbulos están limpios y abiertos).

1 = Mínimo barro dentinario (existe una capa mínima de barro dentinario y más del $50 \%$ de los túbulos dentinarios están visibles).

2 = Moderado barro dentinario (existe una capa moderada de barro dentinario y hay menos del 50\% de túbulos dentinarios abiertos).

3 = Abundante barro dentinario (el barro dentinario cubre la superficie de la pared y los túbulos).

Se utilizó la escala propuesta por Torabinejad y cols. ${ }^{3}$ para analizar el grado de erosión:

$1=$ Sin erosión (todos los túbulos con apariencia y tamaño normal).

2 = Erosión moderada (la dentina peritubular fue erosionada).

3 = Erosión severa (la dentina intertubular fue destruida y hay conexión entre los túbulos).

Se comparó el grado de remoción de barro y de erosión entre los distintos irrigantes y entre los tercios del conducto radicular. Para cada conjunto de datos se reportó el número de observaciones, mediana, media, desviación estándar, frecuencia absoluta y porcentaje de los distintos valores de puntuación. Las comparaciones de puntuación se realizaron mediante la prueba de Kruskal-Wallis. Cuando la prueba arrojó un resultado significativo se realizaron comparaciones entre pares post-hoc. Se fijó nivel de significación del 5\%. Se utilizó el programa Infostat $2016{ }^{10}$ para el análisis de datos. 


\section{Resultados}

Comparación de puntuación para la remoción del barro dentinario entre los distintos irrigantes. (Figuras 1-5) Se encontró una diferencia estadísticamente significativa de puntuación entre los distintos irrigantes utilizados (prueba de Kruskal-Wallis: $p<0,05$ ). En la tabla 1 se describen los resultados de las comparaciones post-hoc.

Se encontraron diferencias significativas entre el grupo control y el resto de los grupos: la puntuación del grupo control fue mayor, hubo menor grado de remoción. También se encontró una diferencia significativa entre el grupo 4 y los grupos 2 y 5: la puntuación del grupo 4 fue menor, hubo mayor grado de remoción. No hubo diferencia significativa entre los grupos 3 y 4 , ni entre los grupos 2, 3 y 5 .

Comparación de puntuación para la remoción del barro dentinario entre tercios del conducto radicular. No se encontraron diferencias significativas de puntuación entre los tercios del conducto radicular (prueba de Kruskal-Wallis: $p=0,07$ ) (Tabla 2).

Comparación de puntuación para el grado de erosión entre los distintos irrigantes. (Figura 6) Se encontró una diferencia estadísticamente significativa de puntuación entre las técnicas de irrigación y los irrigantes utilizados (prueba de Kruskal-Wallis: $p<0,05$ ). En la tabla 3 se describen los resultados de las comparaciones post-hoc.
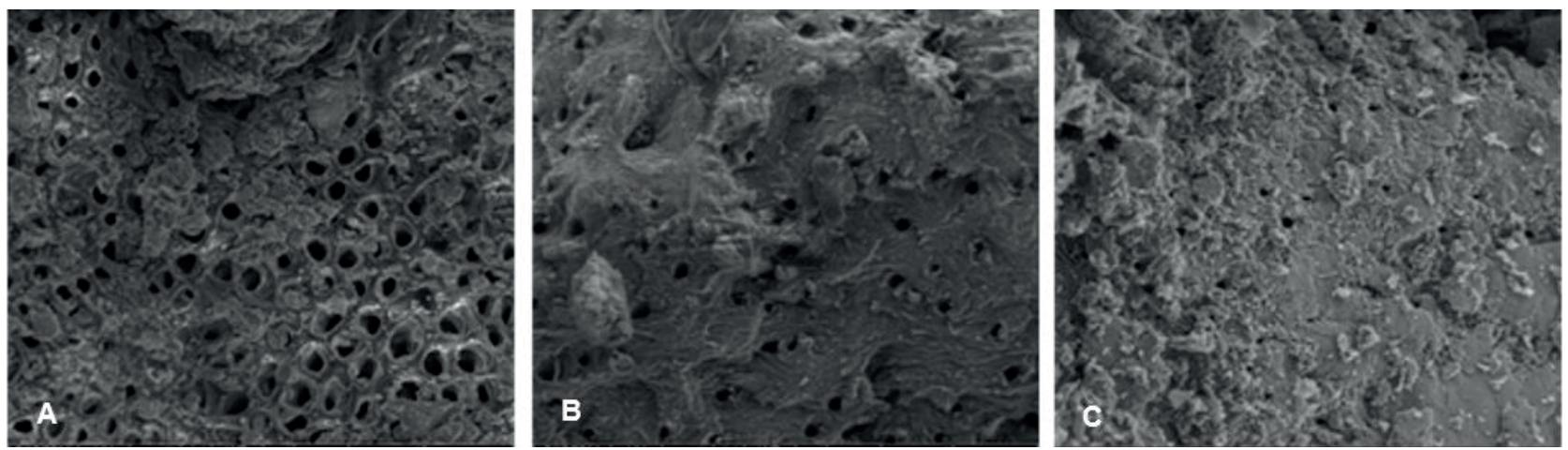

Figura 1. A. Microfotografía de tercio coronario de una muestra del grupo control 1 irrigada con $\mathrm{NaOCl} 5,25 \%$. B. Microfotografía de tercio medio de una muestra del grupo control 1 irrigada con $\mathrm{NaOCl} 5,25 \%$. C. Microfotografía de tercio apical de una muestra del grupo control 1 irrigada con $\mathrm{NaOCl} 5,25 \%$
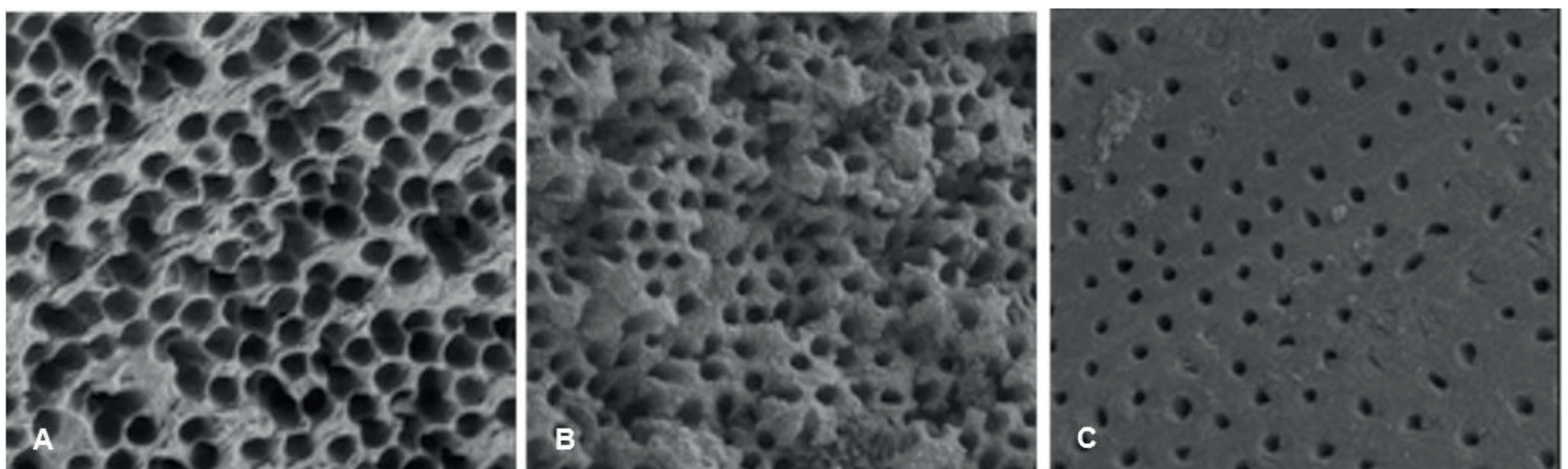

Figura 2. A. Microfotografía del tercio coronario de una muestra del grupo 2 irrigada con NaOCl 5,25\% + EDTA 17\%. B. Microfotografía del tercio medio de una muestra del grupo 2 irrigada con $\mathrm{NaOCl} 5,25 \%+$ EDTA 17\%. C. Microfotografía del tercio apical de una muestra del grupo 2 irrigada con $\mathrm{NaOCl} 5,25 \%+$ EDTA $17 \%$
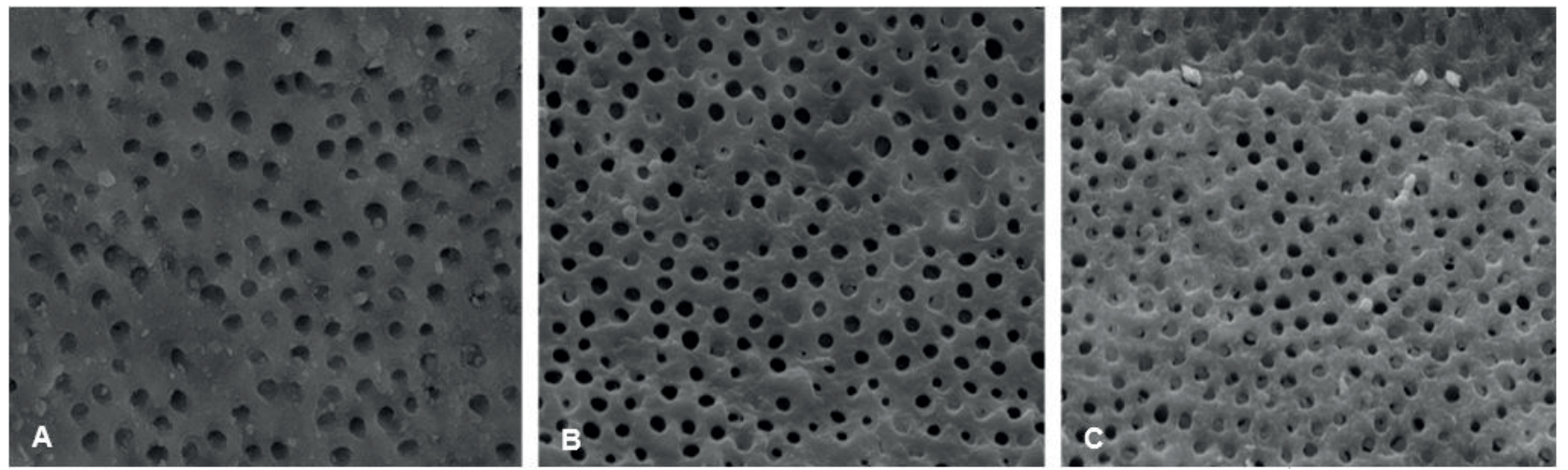

Figura 3. A. Microfotografía de tercio coronario de una muestra del grupo 3 irrigada con $\mathrm{NaOCl} 5,25 \%+$ Ácido maleico $5 \%$. B. Microfotografía de tercio medio de una muestra del grupo 3 irrigada con $\mathrm{NaOCl} 5,25 \%+$ Ácido maleico 5\%. C. Microfotografía de tercio apical de una muestra del grupo 3 irrigada con $\mathrm{NaOCl} 5,25 \%+$ Ácido maleico 5\% 

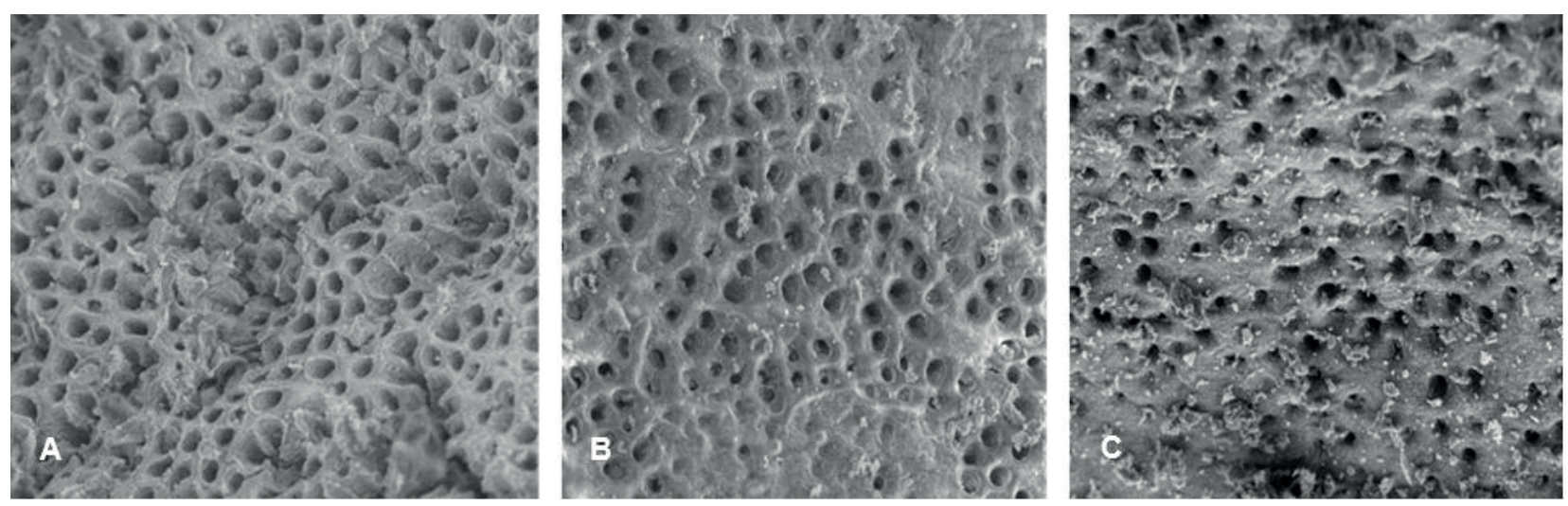

Figura 4. A. Microfotografía del tercio coronario de una muestra del grupo 4 irrigada con $\mathrm{NaOCl} 5,25 \%$ + Ácido cítrico $10 \%$. B. Microfotografía del tercio medio de una muestra del grupo 4 irrigada con $\mathrm{NaOCl} 5,25 \%$ + Ácido Cítrico $10 \%$. C. Microfotografía del tercio apical de una muestra del grupo 4 irrigada con $\mathrm{NaOCl} 5,25 \%+$ Ácido cítrico $10 \%$
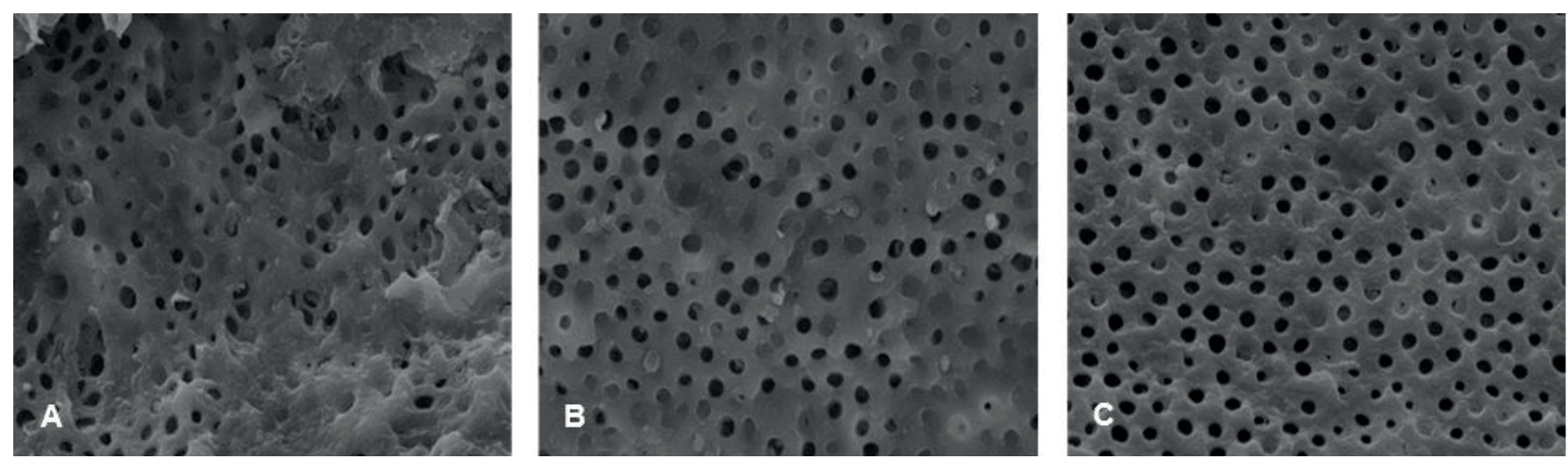

Figura 5. A. Microfotografía del tercio coronario de una muestra del grupo 5 irrigada con $\mathrm{NaOCl} 5,25 \%+$ Ácido fosfórico $37 \%$. B. Microfotografía del tercio medio de una muestra del grupo 5 irrigada con $\mathrm{NaOCl} 5,25 \%+$ Ácido fosfórico 37\%. C. Microfotografía del tercio apical de una muestra del grupo 5 irrigada con $\mathrm{NaOCl}$ 5,25\% + Ácido fosfórico 37\%

Tabla 1. Comparación de score para la remoción del barro dentinario entre los distintos irrigantes mediante la prueba de Kruskal-Wallis, seguida por comparaciones de a pares (post-hoc). Grupos sin ninguna letra común presentan diferencias significativas de puntuación $(p<0,05)$

\begin{tabular}{|c|c|c|c|c|c|c|c|c|c|}
\hline \multicolumn{10}{|c|}{ Remoción del barro dentinario y soluciones irrigantes } \\
\hline Tipo de irrigante & Variable & $\mathbf{n}$ & Mediana & Media & $\mathrm{DE}$ & gl & $\mathbf{H}$ & $\mathrm{p}$ & post-hoc \\
\hline 1 (Control) & \multirow{5}{*}{ Puntuación } & 18 & 3 & 79 & 0 & 4 & 46,64 & $<0,05$ & a \\
\hline 2 & & 18 & 2 & 49 & 23 & & & & $\mathrm{~b}$ \\
\hline 3 & & 18 & 0 & 33 & 15 & & & & $\mathrm{bc}$ \\
\hline 4 & & 18 & 0 & 24 & 9 & & & & c \\
\hline 5 & & 18 & 1 & 42 & 22 & & & & $\mathrm{~b}$ \\
\hline
\end{tabular}

Tabla 2. Comparación de score para la remoción del barro dentinario entre tercios del conducto radicular mediante la prueba de Kruskal-Wallis

\begin{tabular}{ccccccccc}
\hline \multicolumn{7}{c}{ Remoción del barro dentinario y tercio radicular } \\
\hline Tercio radicular & Variable & $\mathbf{n}$ & Mediana & Media & DE & gl & H & p \\
\hline Coronario & Puntuación & 30 & 0 & 37 & 24 & 2 & 4,78 & 0,07 \\
Medio & 30 & 1 & 47 & 24 & & & \\
Apical & 30 & 1 & 52 & 24 & & & \\
\hline
\end{tabular}



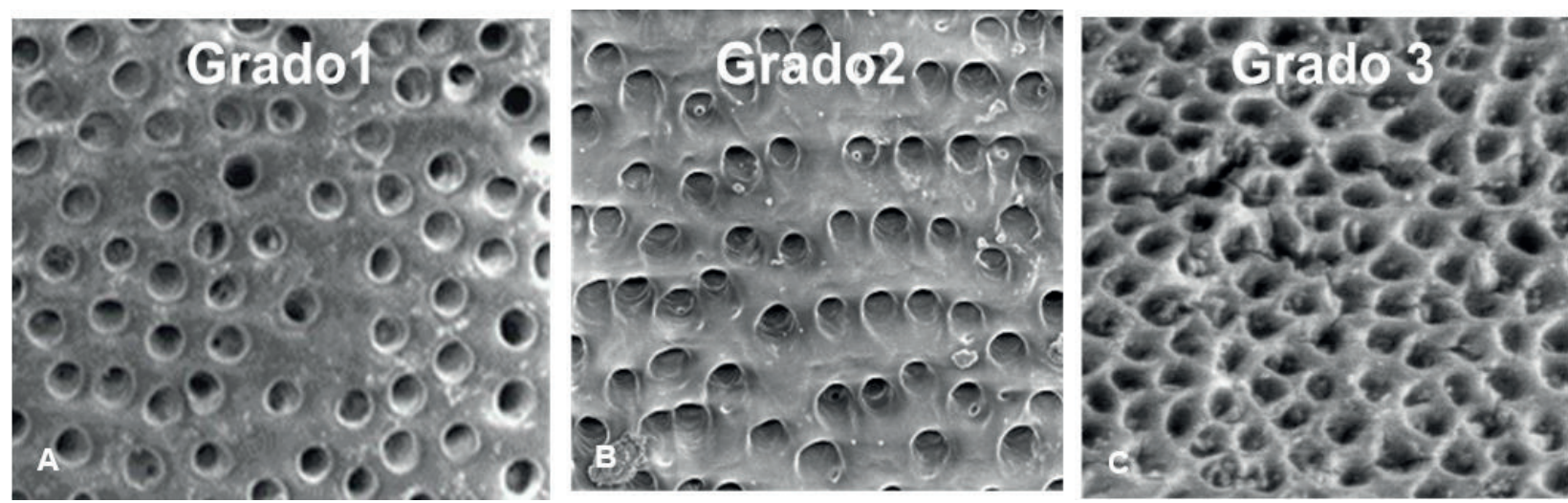

Figura 6. A. Microfotografía correspondiente al grado 1 de erosión. B. Microfotografía correspondiente al grado 2 de erosión. C. Microfotografía correspondiente al grado 3 de erosión

Tabla 3. Comparación de score para la remoción del barro dentinario entre los distintos irrigantes mediante la prueba de Kruskal-Wallis, seguida por comparaciones de a pares (post-hoc). Grupos sin ninguna letra común presentan diferencias significativas de puntuación $(p<0,05)$

\begin{tabular}{|c|c|c|c|c|c|c|c|c|c|}
\hline \multicolumn{10}{|c|}{ Erosión y soluciones irrigantes } \\
\hline Tipo de irrigante & Variable & $\mathbf{n}$ & Mediana & Media & DE & gl & $\mathbf{H}$ & $\mathrm{p}$ & post-hoc \\
\hline 1 (Control) & Puntuación & 18 & 1 & 27 & 0 & 4 & 32,91 & $<0,05$ & a \\
\hline 2 & & 18 & 1 & 40 & 21 & & & & a \\
\hline 3 & & 18 & 1 & 32 & 14 & & & & a \\
\hline 4 & & 18 & 3 & 64 & 22 & & & & $\mathrm{~b}$ \\
\hline 5 & & 18 & 2 & 65 & 20 & & & & $\mathrm{~b}$ \\
\hline
\end{tabular}

Tabla 4. Comparación de score para la erosión entre tercios del conducto radicular mediante la prueba de Kruskal-WaIlis

\begin{tabular}{ccccccccc}
\hline \multicolumn{7}{c}{ Erosión $\mathbf{y}$ tercio radicular } \\
\hline Tercio radicular & Variable & $\mathbf{n}$ & Mediana & Media & DE & gl & H & p \\
\hline Coronario & Puntuación & 30 & 2 & 51 & 24 & 2 & 2,62 & 0,19 \\
Medio & & 30 & 1 & 46 & 24 & & & \\
Apical & & 30 & 1 & 40 & 21 & & & \\
\hline
\end{tabular}

No se encontraron diferencias significativas de erosión entre los grupos 1, 2 y 3; ni entre los grupos 4 y 5 . Los grupos 1,2 y 3 mostraron diferencias significativas con respecto a los grupos 4 y 5 : los valores de puntuación de erosión fueron mayores en los grupos 4 y 5 , hubo mayor grado de erosión.

Comparación de puntuación para el grado de erosión entre tercios del conducto radicular. No se encontraron diferencias significativas de puntuación entre los tercios del conducto radicular (prueba de Kruskal-Wallis: $p=0,19)$ (Tabla 4).

\section{Discusión}

La efectividad de la técnica de irrigación pasiva está directamente relacionada con la capacidad de remoción del tejido orgánico e inorgánico que posee el irrigante, con la frecuencia con que se realiza la irrigación, con el volumen empleado, con la temperatura utilizada y con la cercanía a la constricción apical con la que se profundiza la aguja dentro del conducto.
El EDTA al 17\% y con pH 7 facilita el acceso a los conductos muy estrechos y curvos porque altera la permeabilidad y solubilidad de la dentina y descalcifica hasta una profundidad de $40 \mu \mathrm{m}{ }^{8}$. El tiempo óptimo de trabajo de los agentes quelantes es incierto ? Se reportó efectividad de remoción en un tiempo de trabajo de entre 1 y 5 minutos ${ }^{11}$. Un estudio realizado por Calt y cols. ${ }^{12}$, reportó que 1 minuto de exposición con $10 \mathrm{ml}$ de EDTA al 17\%, removió la capa de barro dentinario, pero si se exponía durante 10 minutos ocasionaba una excesiva erosión tanto a nivel peritubular como intertubular.

Mello y cols. ${ }^{13}$, no encontraron diferencias en el grado de remoción de la capa de barro al utilizar $5 \mathrm{ml}, 10 \mathrm{ml} \mathrm{y}$ $15 \mathrm{ml}$ de EDTA al 17\%, como último irrigante.

Los resultados alcanzados en este trabajo coinciden con los de un estudio realizado por Clarkson y cols. ${ }^{14}$, quienes encontraron un mayor grado de erosión al utilizar la combinación de EDTA al 17\% con $\mathrm{NaOCl} 5,25 \%$, que al usar solamente EDTA al 17\%. 
En este estudio se realizó una irrigación secuencial y protocolizada con hipoclorito de sodio y diferentes soluciones quelantes para mantener la acción disolvente que posee el hipoclorito de sodio. Hubo coincidencia con lo reportado por Grawehr y cols. ${ }^{15}$, quién establece que al combinar EDTA con hipoclorito de sodio se afecta la capacidad de disolución de tejido orgánico que posee el hipoclorito porque no hay clorina libre en esa combinación, por lo tanto, recomienda su uso por separado en un régimen alternado y utilizando copiosas cantidades de agua destilada estéril como irrigación final para eliminar los precipitados que pudieran haberse formado ${ }^{15}$.

$\mathrm{Al}$ igual que lo reportado por Baumgartner y cols. ${ }^{16}$, se pudo observar en este trabajo que la combinación de hipoclorito de sodio al 5,25\% más ácido cítrico al 10\%, fue efectiva para la eliminación de la capa de barro depositada sobre las paredes instrumentadas.

Según lo establecido por Kuruvilla y cols. ${ }^{17}$, el ácido maleico al $7 \%$ y el EDTA al $17 \%$ presentan una eficacia similar de remoción de la capa de barro. El ácido maleico al 7 \% comparándolo con el EDTA 17\%, descalcificó la dentina radicular con mayor secuestro de iones calcio y fósforo durante los primeros cinco minutos ${ }^{9}$.

Dada su acidez, el ácido maleico tiene un mejor efecto desmineralizante y actúa en un período de tiempo más corto. Sin embargo, Prabhu y cols. ${ }^{6}$ informaron que cuando se utilizó en una concentración superior al 7\% causó daño en la dentina intertubular.

Las soluciones de ácido cítrico en concentración del 5\% y $10 \%$ tienen la capacidad de extraer los iones calcio de la matriz dentinaria y una actividad antibacteriana comparable o mejor que la del EDTA al 17\%, el cual es considerado como el quelante de referencia en endodoncia ${ }^{9,18}$.

El tiempo de exposición de la dentina al ácido cítrico debe ser de 1 a 3 minutos, lo suficiente como para lograr la eliminación completa de la capa de barro dentinario, pero no excesivo porque produce erosión de la dentina peritubular, debido a que esta posee un elevado contenido de sales de calcio y es la zona donde el ácido presenta un mayor grado de acción ${ }^{9}$. La dentina intertubular en cambio presenta mayor cantidad de colágeno por eso actúa menos sobre ella ${ }^{19}$. En el presente trabajo se lo utilizó durante 1 minuto para minimizar la acción erosiva que producen las soluciones ácidas.

El hipoclorito de sodio utilizado en secuencia alternada con el ácido cítrico o el EDTA redujo significativamente el riesgo de ataque químico en la dentina por la neutralización química de ambos agentes 9,20,21.

Los resultados obtenidos en este estudio muestran que, el uso de combinaciones de irrigantes logró, en diferentes grados, la limpieza en las paredes del conducto radicular. Si bien, con la combinación de irrigantes se logró ver túbulos dentinarios abiertos, la diferencia cualitativa se observó en la limpieza de la dentina intertubular. La misma, cuando se usó hipoclorito de sodio al 5,25\% + ácido cítrico al $10 \%$, se visualizó limpia y con trama de fibras colágenas expuestas.
Un trabajo realizado por Pérez y cols. ${ }^{22}$, reportó que la combinación de $\mathrm{NaOCl} 2,5 \%$ con ácido fosfórico 5\% fue menos eficiente en la remoción del barro dentinario que la combinación $\mathrm{NaOCl} 2,5 \%$ y ácido cítrico 15\%. Los resultados obtenidos en este estudio difieren con los alcanzados por este autor porque las combinaciones de $\mathrm{NaOCl} 5,25 \%$ + ácido fosfórico $37 \%$ e $\mathrm{NaOCl} 5,25 \%$ + ácido cítrico $10 \%$ presentaron igual grado de remoción de la capa de barro. Esto podría deberse a que en este trabajo se utilizó una mayor concentración de ácido fosfórico (37\%).

Por su parte, Garberoglio y cols. ${ }^{23}$, observaron que tanto la combinación de ácido cítrico al 10\% y ácido fosfórico al 24\%, como el uso del EDTA al 17\% y $3 \%$ eran efectivos en la remoción de la capa de barro cuando se utilizaban como últimos irrigantes, sin observarse diferencias significativas entre ellos. El EDTA mostró menor efecto desmineralizante que las soluciones ácidas. El presente trabajo difiere con los resultados mencionados dado que el ácido fosfórico 37\% presentó un mejor grado de remoción de la capa de barro que el EDTA $17 \%$, pero coinciden en que tanto el ácido fosfórico $37 \%$ como el ácido cítrico $10 \%$ produjeron el mayor grado de desmineralización. El bajo pH de estas soluciones irrigantes podría generar un efecto adverso sobre los tejidos periapicales, si las mismas se extruyeran del conducto radicular.

En el estudio de Pérez y cols. ${ }^{22}$ se evaluó y comparó ex vivo, el grado de descalcificación dentinaria generado por soluciones de EDTA 15\%, ácido cítrico 15\% y ácido fosfórico $5 \%$, no observándose diferencias estadísticamente significativas entre el EDTA 15\% y el ácido cítrico $15 \%$, en un período de tiempo de 10 minutos. Se encontraron diferencias significativas a favor del EDTA $15 \%$ y del ácido cítrico $15 \%$ al comparar estos grupos con el ácido fosfórico 5\%, en el mismo período de tiempo. El presente trabajo difiere con los resultados mencionados porque no se encontraron diferencias significativas en el grado de erosión generado por el ácido maleico 5\% y el EDTA $17 \%$; como tampoco se encontraron diferencias significativas entre el ácido fosfórico $37 \%$ y el ácido cítrico $10 \%$. Pero hubo diferencias significativas de erosión a favor del ácido maleico 5\% y el EDTA $17 \%$ con respecto al ácido fosfórico $37 \%$ y al ácido cítrico $10 \%$, el grado de erosión fue mayor al utilizar estas dos últimas soluciones ácidas.

Prado y cols. ${ }^{24}$ evaluaron la cantidad de barro dentinario generado por la instrumentación rotatoria y el grado de remoción del mismo realizado por diferentes soluciones quelantes, y observaron que el uso de ácido cítrico al 10\%, sólo eliminó el barro en forma parcial, mientras que al utilizarlo en concentración del 32\% la remoción fue total.

En este trabajo se utilizó técnica de irrigación pasiva con jeringa plástica descartable y aguja de 30 gauges de dispersión lateral. Se considera que es un sistema de irrigación con flujo laminar, menos eficiente que los sistemas activos pero sigue siendo ampliamente aceptado y utilizado por la mayoría de los odontólogos genera- 
les, como así también por muchos endodoncistas 9,25. Es una técnica relativamente sencilla, en la cual es fácil de controlar la profundidad de la aguja y el volumen que se dispensa de irrigante. Se usó aguja de 30 gauges porque se consideró que alcanza una buena penetración con lo que se obtiene una buena limpieza del conducto radicular, con bajo riesgo de extrusión ${ }^{9,26}$. Por su parte Boutsioukis y cols. ${ }^{27}$, establecen mediante tomografía computarizada que las agujas de irrigación con orificio lateral deben colocarse a un milímetro de la longitud de trabajo para permitir una correcta limpieza del tercio apical, dado que el irrigante no fluye más allá de un milímetro del extremo de la misma, al realizar técnica de irrigación pasiva.

La incorporación del ácido maleico combinado con el hipoclorito de sodio, ha cubierto satisfactoriamente una de las expectativas más importantes que tiene la endodoncia sobre la pared del conducto radicular como es eliminar el barro dentinario, cosa que no se logra totalmente con la combinación del hipoclorito de sodio y el EDTA, habitualmente utilizados en los protocolos de rutina.

Esto alienta una expectativa de nuevas investigaciones a futuro con ácido maleico considerando nuevos tiempos de aplicación, diferentes concentraciones y el agregado de sustancias que puedan actuar como estabilizadores del colágeno y disminuyan la profundidad de desmineralización de la dentina, como iones de calcio, hierro y aluminio que poseen algunos grabadores empleados en operatoria dental.

Hasta el momento en la literatura se ha dado poca importancia a la erosión que ocasionan las soluciones ácidas sobre los túbulos dentinarios al tratar la pared. La relevancia del presente trabajo es haber demostrado que el ácido maleico elimina el barro dentinario en el tercio apical del conducto, manteniendo sin erosión la estructura del sustrato dentinario.

Se puede concluir que los resultados obtenidos sugieren que la combinación de $\mathrm{NaOCl} 5,25 \%$ + ácido maleico $5 \%$ produce el mayor grado de remoción de barro dentinario con menor grado de erosión. Por otro lado, las combinaciones de $\mathrm{NaOCl} 5,25 \%$ + ácido fosfórico $37 \%$ e $\mathrm{NaOCl} 5,25 \%$ + ácido cítrico $10 \%$ producirían el mayor grado de erosión. No hubo diferencia significativa por tercios radiculares al evaluar remoción del barro dentinario y erosión sobre las paredes del conducto.

\section{Agradecimientos}

Las autoras agradecen a la microscopista del departamento de Mecánica del Instituto Nacional de Tecnología Industrial (INTI), Srta. Soledad Pereda, por la toma de las imágenes de microscopía electrónica de barrido ambiental que ilustran este trabajo y que permitieron obtener los resultados que se reportan.

\section{Referencias bibliográficas}

1. Schneider SW. A comparison of canal preparations in straight and curved root canals. Oral Surg Oral Path Oral Med. 1971;32:271-5.
2. Rome WJ, Doran JE, Walter WA. The effectiveness of glyoxide and sodium hypoclorite in preventing smear layer formation. J Endod.1985;11(7):281-8.

3. Torabinejad M, Handysides R, Khademi A, Bakland LK. Clinical implications of smear layer in endodontics: A review. Oral Radiol Endod. 2002;94:658-66.

4. Hulsmann M. Effects of mechanical instrumentation and chemical irrigation on the root canal dentin and surrounding tissues. Endod Top. 2013;29(1):55-86.

5. Ballal NV, Kundabala M, Kadengodlu S. Evaluation of the Effect of Maleic Acid and Ethylenediaminetetraacetic Acid on the Microhardness and Surface Roughness of Human Root Canal Dentin. J Endod. 2010:36(8):13858.

6. Prabhu SG, Rahim N, Bhat KS, Mathew J. Comparison of removal of endodontic smear layer using $\mathrm{NaOCl}$, EDTA, and different concentrations of maleic acid-A SEM study. Endodontology. 2003;15:20-5.

7. Gambarini G, De Luca M, Gerosa R, Cavalleri G. In vitro cytotoxicity of chelanting agents for endodontic use. J Dent Res. 1997;76 (Special Issue IADR), 136 (abstract), p 79.

8. Di Lenarda R, Cadenaro M, Sbaizero O. Effectiveness of 1 mol-1 citric acid and 15\% EDTA irrigation on smear layer removal. Int Endod J. 2000;33:46-52.

9. Jimenez-Chaves V, Labarta AB, Gualtieri A, Sierra LG. Evaluación de la remoción del barro dentinario al utilizar ácido cítrico al 1\% y Rc Prep como soluciones irrigantes. Estudio con microscopio electrónico de barrido. Rev. Cient Odont. 2013;9(1):31-40.

10. Di Rienzo JA, Casanoves F, Balzarini MG, Gonzalez L, Tablada M, Robledo CW. InfoStat versión 2016, Grupo InfoStat, FCA, Universidad Nacional de Córdoba, Argentina. 2016. URL http://www.infostat.com.ar

11. Khedmat S, Noushin S, Comparison of the Efficacy of Three Chelating Agents in Smear Layer Removal. J Endod. 2008;34(5):599-602.

12. Calt SA. Time dependent effects of EDTA on dentin structures. J Endod. 2002; 28:17-9.

13. Mello I, Antoniazzi JH, Coil J. Influence of different volume of EDTA for final rinse on smear layer removal. Oral Surg. 2008;106:40-3.

14. Clarkson RM, Podlich, HM, Moule AJ. Influence of Ethylenediaminetetraacetic Acid on the Active Chlorine Content of Sodium Hypochlorite Solutions When Mixed in Various Proportions. J Endod. 2011;37:53843.

15. Grawehr M, Sener B, Waltimo T, Zehnder M. Interactions of ethylenediamine tetraacetic acid with sodium hypochlorite in aqueous solutions. Int Endod J. 2003;36:411-15.

16. Baumgartner JC, Brown CM, Mader C, Peters D, Shulman J. A Scanning Electron Microscopic Evaluation of Root Canal Debridement using Saline, Sodium Hypochlorite, and Citric Acid. J Endod. 1984;10:525-31.

17. Kuruvilla A, Jaganath BM, Krishnegowda, Ramachandra PKM, Johns DA, y Abraham A. Una evaluación comparativa de la eliminación de la capa de frotis mediante 
el uso de EDTA, ácido etidronic, y ácido maleico como irrigantes del conducto radicular: In vitro. J Conserv Dent. 2015;18(3):247-51.

18. Yamaguchi M, Yoshida K, Suzuki R, Nakamura H. Root canal irrigation with citric acid solution. J Endod. 1996;22(1):27-9.

19. Haznedaroğlu F. Efficacy of various concentrations of citric acid at different $\mathrm{pH}$ values for smear layer removal. Oral Surg Oral Med Oral Path Oral Rad Endod J. 2010;96 (3):340-4.

20. Martinelli S, Strehl A, Mesa M. Estudio de la eficacia de diferentes soluciones de EDTA y ácido cítrico en la remoción del barro dentinario. Odontoestomatología. 2012; 14(19):52-63.

21. Martos J, Rodo Osinaga PW, Paz Borda D. Evaluación del efecto de hipoclorito de sodio, EDTA y ácido cítrico en la permeabilidad dentinaria. Rev Esp Endod. 2003;21(3):174-8.

22. Perez-Heredia M, Ferrer-Luque CM, Gonzalez-Rofriguez MP. The effectiveness of different acid irrigating solutions in root canal cleaning after hand and rotary instrumentation. J Endod. 2006;32:993-7.

23. Garberoglio R, Becce C. Smear layer removal by root canal irrigants. Oral Surg Oral Med Oral Pathol. 1994;78:359-67.

24. Prado M, Gusman H, Gomes B, Simao RA. Scanning Electron Microscopic investigation of the effectiveness of phosphoric acid in smear layer removal when compared whit EDTA and citric acid. J Endod. 2011;37:255-8.

25. Muñoz HR. In vivo efficacy of three different endodontic irrigation systems for irrigant delivery to working length of mesial canals of mandibular molars. J Endod. 2012;38:445-8.

26. Jiang L, Lak B, Eijsvogels LM, Wesselink P, van der Sluis LWM. Comparison of the cleaning efficacy of different final irrigation techniques. J Endod. 2012;38:838-41.

27. Boutsioukis CLT, Kastrinakis E, Wesselink PR, Lucas WM, Van der Sluis. The effect of Needle-insertion depth on th eirrigant flow the root canal: Evaluation using an unsteady computational fluid dynamics model. J Endod. 2010;36:1664-8. 
